\title{
Editorial
}

\section{The Decline of Pluralism in Medicine: Dissent Is Welcome}

\author{
Giovanni A. Fava \\ Department of Psychiatry, University at Buffalo, State University of New York, Buffalo, NY, USA
}

In his landmark book "The Structure of Scientific Revolutions" [1], Thomas Kuhn outlines the importance of intellectual pluralism and challenge of current paradigms. "Novelty emerges only with difficulty, manifested by resistance, against a background provided by expectation" $[1, \mathrm{p}$ 64]. The intellectual capital of medicine is the creativity linking research and clinical practice. The development of models that may entail better explanations of clinical phenomena and of innovations in clinical practice strictly depends on this interaction and on the pluralism of viewpoints $[2,3]$. However, such interaction is increasingly threatened by several converging developments.

A first obstacle comes from the world of publishing. Open access is only open to readers and not to potential contributors, since these latter have to pay for publishing. This means limiting the opportunity to publish to authors whose work is supported by grants and/or to those who are loaded with conflicts of interest and have private firms behind them, and/or those who work in institutions that may pick up the bill. Truly innovative research, however, is unlikely to be funded, also by public sources. Further, the reporting of side effects which may occur serendipitously is also unlikely to be funded. Creative investigators, particularly in their initial phase, may thus encounter difficulties in communicating their insights and pilot data that are likely to trigger changes in paradigms. They clash against the commercial nature of open-access journals

\section{KARGER}

() 2019 S. Karger AG, Basel

E-Mail karger@karger.com

www.karger.com/pps
[3]. Another trend that conflicts with pluralism is the tendency to include as many influential authors as possible in position and/or review papers. Consensus has replaced specific contribution in these papers; authors are looking for increasing their $h$ index, and collective papers that entail the considerable support of self-citation by an influential group seem to be perfect for achieving this goal. Those who do not subscribe to these totalitarian views are likely to be emarginated. Further, they find an additional source of obstacles in expressing dissenting views: more and more journals have eliminated or reduced their correspondence sections, which may provide the opportunities for important debates.

A second source of increasing difficulties for pluralism of viewpoints comes from corporate interests that result in self-selected academic oligarchies (special interest groups). Members of special interest groups, by virtue of their financial power and close ties with other members of the group, have the task of systematically preventing dissemination of data which may be in conflict with their interests [3]. The first target is to undermine the critical individual judgment of the physicians through massive doses of censorship. Censorship may take different forms: direct suppression of information by special interest groups who act as editors and reviewers or make choices in scientific programs; careful selection of the literature in a biased direction and manipulated interpretation of clinical trials (including those supported by public sourc- 
es); self-censorship (when an investigator omits raising questions and criticism for the fear of retaliation) [3]. Mediocrity supports the power structure, which in turn rewards it adequately [4]. Reviews are then rigorously ghostwritten, with as many key opinion leaders as possible as authors (better if they do not even remember or realize what they have signed, as I had the opportunity to verify in many cases by casual chats and do not raise doubts or concerns that may affect prescription practices). And, again, lack of visibility of dissent opportunities (correspondence) also contributes to the spectacular achievements of propaganda.

A third obstacle to the achievement of pluralism comes from the current characterization of evidence-based medicine (EBM), which is quite different from its original purposes [5]. There is excessive reliance on randomized controlled trials (RCT) and meta-analyses that are not intended to answer questions about the treatment of individual patients [6]. The results of RCT may show comparative efficacy of treatments for the average randomized patient but not for those whose characteristics such as severity of symptoms, comorbidity, and other clinical features depart from standard presentations $[5,6]$. Feinstein [7] compared meta-analyses to the alchemy that existed before modern scientific chemistry. The analogy was the hope to convert existing things into something better (changing base metals into gold) and the work with material that was heterogeneous and poorly identified. Indeed, meta-analyses often include highly heterogeneous studies and ascribe conflicting results to random variability, whereas different outcomes may reflect different patient populations and enrollment and protocol characteristics [8]. Not surprisingly, the results of metaanalyses tend to collide [9] and are of limited usefulness for informing patient care [8]. Meta-analyses, however, are on the rise: from fewer than 1,000 a year in 2000 to about 11,000 in 2017, with about one-third of them performed in China [9]. Further, the pseudo-objectivity of systematic reviews, obtained by increasingly complicated and cumbersome procedures, where the presence of an author with clinical familiarity with the topic is optional, is often associated with intellectual poverty. A frequent conclusion is then that the evidence is too limited and further studies are needed, as was found to be the case in more than half of Cochrane reviews [10]. And the prodigal experts, often of young age, who sign (do not certainly write) an impressive number of papers per year, have never performed a specific investigation and/or given an original contribution to the literature. They lack the clinical insights that only getting part of an investigation may yield and yet rapidly climb the academic stairs and become opinion leaders, supported by the cult of mediocrity [4].

Lack of familiarity of researchers with clinical practice is the basis for the current intellectual crisis of medical research [5], which was identified by Feinstein more than four decades ago [11]. The fundamental source of research questions (with the ensuing development of hypotheses to be validated) is no longer clinical [11]. In clinical practice, different emphases and pathophysiological interpretations of the phenomena that are encountered exist. As Gordon Guyatt [12] remarks, there is no single right decision in a specific clinical situation and one should evaluate the potential harms and risks of each therapeutic act. Indeed, the model of EBM was originally articulated in a way that highlighted the many sources of knowledge and how they could be integrated with judgment in the shared decisions for the care of the whole person [13]. However, in the following years, vested interests and lack of familiarity with clinical issues conveyed the message that there is only one option for treatment of a specific condition. The totalitarian derive of EBM clearly emerges when dissenting views are expressed, as the expulsion of Peter Gotzsche from Cochrane [14] reminds us vividly. The clinician needs to have a clear account of the potential benefits of a specific treatment as well as of the predictors of responsiveness, and of the potential adverse events that may be triggered by the therapeutic act [13]. Yet, meta-analyses are geared to the average patient and to highlight only benefits. Such tendency is even more pronounced with umbrella and network meta-analyses $[5,8]$. Commercial interests may further drive this tendency [5]. The net result is the production of authoritarian guidelines, with the suppression of pluralism. In such guidelines, endorsed by scientific societies liable to conflicts of interest [3], the prescribing clinician is driven by an overestimated consideration of potential benefits, paying little attention to the likelihood of responsiveness and to potential vulnerabilities in relation to the adverse effects of treatment [5].

The psychiatric field offers a good illustration of this intellectual crisis [15]. Ebrahim et al. [16] examined conflicts of interest in meta-analyses concerned with antidepressant drugs. In nearly two-thirds of cases, authors were either employees of the assessed drug manufacturer or had some industry links. In these cases, negative or simply cautionary statements in the concluding statement of the abstract were unlikely to appear [16]. A the same time, physicians were taught to misinterpret clinical phenomena linked to the dependence produced by anti- 
depressant drugs. Iatrogenic manifestations of behavioral toxicity, such as withdrawal syndromes and persistent postwithdrawal disorders [17], have been censored and denied proper funding and attention. Funds have been diverted to research with little relevance to health outcomes, such as those looking for pretreatment biological predictors [18], which are of questionable value since neurobiological assets change throughout the course of illness [17].

How can we stop and revert the decline of pluralism in clinical medicine? An important contribution may come from medical journals, which should not be afraid to host dissent, debates, and heresy, as long as they are supported by methodological soundness. Beliefs and practice contrary to the orthodox doctrine, to what is normally accepted and maintained, may be a valuable source of conceptual progress [1]. If we silence heretics (according to the Greek root of the word, people who make their own choices), we are condemned to intellectual stagnation. The financial support of a journal (whether subscriptionor contributor-based or based on external support, such as those with pharmaceutical advertisements) may determine its degree of intellectual autonomy [3, 19].

As important, however, is the contribution that investigators may yield. EBM does not represent the scientific approach to medicine: it is only one of the possible interpretations of the scientific approach to clinical practice [5]. EBM is in need of clinical strategies and integration. One may wonder whether the answers to specific clinical questions are likely to come from larger and larger RCTs with broad inclusion criteria (e.g., a major depressive disorder), whose findings are then synthesized and compared to those of other trials by meta-analyses or, even worse, umbrella meta-analyses [20]. Or whether an intervention can be evaluated by a series of small trials [21] that deal with specific clinical populations in terms of clinical characterization (e.g., depression subtypes) or treatment history (e.g., a certain type and duration of previous pharmacotherapy). Under ordinary conditions, in fact, patients are included in a trial regardless of their treatment history. Yet, a major source of spurious findings is the limited awareness of the fact that the current patient's symptomatology may have developed over the years and have reflected previous treatments [20]. The term "iatrogenic comorbidity" refers to the lasting detrimental effects that previous treatments may entail, that may affect prognosis and response to therapy, and that are worth exploring in specific trials [20]. Another important integration to EBM may come from the recently developed medicine-based evidence (MBE) [22, 23]. MBE provides the biological and biographical basis of precision medicine. It builds on the archive of patient profiles using data from all study types and data sources, including both clinical and socio-behavioral information. The clinician seeking guidance for the management of the individual patient will start with the patient's longitudinal profile and find matches in the archive, which provides an important source of therapeutic pluralism [22, 23]. Both small series of RCT and the archives of MBE may shed some light on the neglected issue of iatrogenic factors in illness configuration [24]. It is simply astonishing that, at a time of medication overload [25], iatrogenic comorbidity is substantially ignored when formulating treatment plans.

Additional support to pluralism in medicine may come from funding agencies. Most of funded research involves trite variations on tired themes. It seldom rewards innovative efforts (a remarkable exception is concerned with such grants in Germany). Looking for innovations should become a priority for public agencies.

Finally, the ascent of prodigal experts involved in a countless number of meta-analyses and systematic reviews is currently facilitated by current mechanisms of academic promotion, which often do not take into sufficient account the value of original investigations. True talent is threatening because it is frequently associated with independent thinking, which undermines the power structure, while mediocrity assures lifetime commitment [4]. Fighting the cult of mediocrity is the ultimate pathway to fostering pluralism in clinical research.

Thomas Kuhn [1] clarified that scientific revolutions are initially restricted to a small segment of the scientific community but progressively lead to a more general awareness that a paradigm that had previously led the way has ceased to function adequately. Preservation of and support to pluralism is the key to addressing the increasing challenges of current clinical research.

\section{Appendix}

The journal has reached a top impact factor (IF) in 2018 (13.74) and continues its growth. The new IF places Psychotherapy and Psychosomatics as fourth in the Science Citation Index Psychology and Psychiatry rankings. These rankings, however, do not differentiate whether a journal is exclusively concerned with review articles (which are more likely to be cited) or publishes also original investigations. In the Science Citation Index Psychology ranking, the 3 journals preceding Psychotherapy and Psychosomatics are exclusively dedicated to review articles. This indicates that Psychotherapy and Psychosomatics is the top journal for original investigations in psychology. 
Such achievement is the result of several converging efforts. We first like to acknowledge here the role of the journal's publication manager, Thomas Nold, who retired last year. In the past decades, he gave an outstanding contribution to the journal's growth. We should also acknowledge here the perfect synchrony between Karger's editorial office and the associate editors; the work of the editorial board and statistical consultants; the help of many external reviewers (listed below), who dedicated their time and efforts to assess and improve the quality of submitted manuscripts; the skills of Emanuela Offidani and Andrea Sabbatini, who prepared the press releases of the published articles; the support of our authors and readers.

The following experts have supplemented the editorial board by reviewing the manuscripts submitted to Psychotherapy and Psychosomatics during 2019 and are gratefully acknowledged. Both external referees and editorial board members have disclosed potential conflicts of interests. The Editor-in-Chief and the Associate Editors have no conflicts of interest to declare for 2019.

C. Baethge (Cologne, Germany)

R. Baldessarini (Boston, MA, USA)

R. Bazinet (Toronto, ONT, Canada)

B. Becker (Chengdu, China)

C. Belaise (Bologna, Italy)

G. Benasi (Bologna, Italy)

D. Berle (Sydney, NSW, Australia)

B. Blaskovich (Munich, Germany)

K. Boesen (Lundtoftevej, Denmark)

S. Bratland-Sanda (Bø, Norway)

T. Brockmeyer (Düsseldorf, Germany)

J. Brouillette (Montreal, QC, Canada)

A. Buchholz (Hamburg, Germany)

M. Burton (Atlanta, GA, USA)

R. Calati (Montpellier, France)

J. Camprodon (Boston, MA, USA)

D. Carrozzino (Chieti, Italy)

G. Casu (Bologna, Italy)

L. Choi-Kain (Belmont, CA, USA)

K. Christensen (Aarhus, Denmark)

B. Colagiuri (Sydney, NSW, Australia)

L. Colloca (Baltimore, MD, USA)

M. Constantino (Amherst, MA, USA)

P. Cuijpers (Amsterdam, The Netherlands)

$S$. Dinesen Østergaard (Aarhus, Denmark)

T. Donker (Amsterdam, The Netherlands)

Y. Donmez (Malatya, Turkey)

S. Eisendrath (San Francisco, CA, USA)

A. Evers (Leiden, The Netherlands)

F. Falkenstrom (Linkoping, Sweden)

N. Farrell (Oconomowoc, WI, USA)

C. Fazekas (Graz, Austria)

T. Furukawa (Kyoto, Japan)

C. Gale (Southampton, UK)

E. Garland (Salt Lake City, UT, USA)

S. Gorrell (San Francisco, CA)

S. Gostoli (Bologna, Italy)

M. Greenacre (Barcelona, Spain)

P. Gremigni (Bologna, Italy)

C. Grilo (New Haven, CT, USA)

G. Hafstad (Oslo, Norway)

M. Hedman-Lagerlöf (Stockholm, Sweden)
T. Heidenreich (Esslingen, Germany)

M.P. Hengartner (Zurich, Switzerland)

E. Hertenstein (Bern, Switzerland)

$H$. Himmerich (London, UK)

R. Holt (Southampton, UK)

J. Hong (Boston, MA, USA)

M. Huibers (Amsterdam, The Netherlands)

P. Hurlemann (Bonn, Germany)

K. Jae-Min (Chounan, Republic of Korea)

R.B. Jarrett (Dallas, TX, USA)

E. Joosten (Nijmegen, The Netherlands)

$M$. Kaess (Bern, Switzerland)

E. Kim (Boston, MA, USA)

P. Kirsch (Mannheim, Germany)

J.P. Klein (Lübeck, Germany)

J. Kleinert (Cologne, Germany)

M. Kleinstauber (Auckland, New Zealand)

R. Klinger (Hamburg, Germany)

U. Kramer (Lausanne, Switzerland)

C.H. Kuehner (Mannheim, Germany)

S.L. Kuhlmann (Berlin, Germany)

A.C. LaRue (Charleston, SC, USA)

A. Lang (San Diego, CA, USA)

D. Le Grange (San Francisco, CA, USA)

C. Lemogne (Paris, France)

P. Leombruni (Turin, Italy)

M. Lind (Aarhus, Denmark)

A. Lindahl-Norberg (Stockholm, Sweden)

M. Linden (Berlin, Germany)

R. Lombardo (Caserta, Italy)

M. Lopez Sola (Boulder, CO, USA)

M. Lucente (Bologna, Italy)

U. Lueken (Berlin, Germany)

L. Mallory (San Diego, CA, USA)

K. Martiny (Copenhagen, Denmark)

K. Mathiak (Aachen, Germany)

Y. Matsuoka (Tokyo, Japan)

A. Meier-Creduer (Breunschweige, Germany)

A. Menhert (Leipzig, Germany)

D. Mischoulon (Boston, MA, USA)

M.L. Molendijk (Leiden, The Netherlands)

R. Moynihan (Robina, QLD, Australia)

F.A. Mustafa (Northampton, UK)

H. Möller (Munich, Germany)

Y. Myoungsoon (Seoul, Republic of Korea)

T. Nordgreen (Bergen, Norway)

H. Palma-Gudiel (Barcelona, Spain)

C. Patierno (Rome, Italy)

L. Perogamvros (Geneva, Switzerland)

A. Piedimonte (Turin, Italy)

M. Plöderl (Salzburg, Austria)

R. Procyshyn (Vancouver, BC, Canada)

F. Ramseyer (Bern, Switzerland)

A. Ravindran (Toronto, ONT, Canada)

E. Reilly (Washington, DC, USA)

K. Rickels (Philadelphia, PA, USA)

T. Roth (Detroit, MI, USA)

B. Rothbaum (Atlanta, GA, USA)

P. Ruby (Lyon, France)

L. Sander (Freiburg, Germany) 
M. Schedlowski (Essen, Germany)

C. Schmahl (Mannheim, Germany)

E. Schramm (Freiburg, Germany)

M. Schreuder (Groningen, The Netherlands)

L. Serpell (London, UK)

K. Shaffer (Charlottesville, VA, USA)

M. Simmonds-Buckley (Sheffield, UK)

A. Skvortsova (Leiden, The Netherlands)

D. Sloan (Boston, MA, USA)

N. Sonino (Padova, Italy)

K. Stocker (Zurich, Switzerland)

S. Taubner (Heidelberg, Germany)

T. Titov (Sydney, NSW, Australia)

L. Tondo (Cagliari, Italy)

A. Toussaint (Hamburg, Germany)

M. Valentini (Rome, Italy)
C. Van der Feltz-Cornelis (Heslington, UK)

M. Vasileva (Bremen, Germany)

C. Vazquez (Madrid, Spain)

A. Versace (Pittsburgh, PA, USA)

C. Webb (Belmont, MA, USA)

C. Weise (Marburg, Germany)

M. Wenzel (Berlin, Germany)

$W$. Whitehead (Chapel Hill, NC, USA)

M. Wichers (Groningen, The Netherlands)

$K$. Wingenfeld (Berlin, Germany)

R. Wood (Sydney, NSW, Australia)

M. Woud (Bochum, Germany)

P. Zagorscak (Berlin, Germany)

S. Zerwas (Chapel Hill, NC, USA)

B. Zhu (Bologna, Italy)

M. Zimmerman (Providence, RI, USA)

\section{References}

1 Kuhn TS. The Structure of Scientific Revolutions. 2nd ed. Chicago: University of Chicago Press; 1970.

2 Sniderman AD, Furberg CD. Pluralism of viewpoints as the antidote to intellectual conflict of interest in guidelines. J Clin Epidemiol. 2012 Jul;65(7):705-7.

3 Fava GA. The independence of medical journals and the deceptive effects of open access. Psychother Psychosom. 2014;83(1):1-5.

4 Fava GA. The cult of mediocrity. Psychother Psychosom. 2005;74(1):1-2.

5 Fava GA. Evidence-based medicine was bound to fail: a report to Alvan Feinstein. J Clin Epidemiol. 2017 Apr;84:3-7.

6 Feinstein AR, Horwitz RI. Problems in the "evidence" of "evidence-based medicine". Am J Med. 1997 Dec;103(6):529-35.

7 Feinstein AR. Meta-analysis: statistical alchemy for the 21st century. J Clin Epidemiol. 1995 Jan;48(1):71-9.

8 Concato J, Horwitz RI. Limited usefulness of meta-analysis for informing patient care. Psychother Psychosom. 2019;88(5):257-62.

9 de Vrieze J. The metawars. Science. 2018 Sep; 361(6408):1184-8.

10 Laupacis A, Straus S. Systematic reviews: time to address clinical and policy relevance as well as methodological rigor. Ann Intern Med. 2007 Aug;147(4):273-4.
11 Feinstein AR. The intellectual crisis in clinical science: medaled models and muddled mettle. Perspect Biol Med. 1987;30(2):215-30.

12 Guyatt G. EBM has not only called out the problems but offered solutions. J Clin Epidemiol. 2017 Apr;84:8-10.

13 Richardson WS. The practice of evidencebased medicine involves the care of whole persons. J Clin Epidemiol. 2017 Apr;84:1821.

14 Enserink M. Evidence-based medicine group expels internal critic. Science. 2018 Sep; 361(6408):1173-4.

15 Fava GA. The intellectual crisis of psychiatric research. Psychother Psychosom. 2006;75(4): 202-8.

16 Ebrahim S, Bance S, Athale A, Malachowski C, Ioannidis JP. Meta-analyses with industry involvement are massively published and report no caveats for antidepressants. J Clin Epidemiol. $2016 \mathrm{Feb} ; 70: 155-63$.

17 Fava GA, Cosci F. Understanding and managing withdrawal syndromes after discontinuation of antidepressant drugs. J Clin Psychiatry. Forthcoming 2019 Nov;19com12794.

18 Cuthbert BN. The RDoC framework: facilitating transition from ICD/DSM to dimensional approaches that integrate neuroscience and psychopathology. World Psychiatry. $2014 \mathrm{Feb} ; 13(1): 28-35$.
19 Glassman PA, Hunter-Hayes J, Nakamura T. Pharmacological advertising revenue and physician organizations: how much is too much? West J Med. 1999;171:234-8.

20 Fava GA, Tomba E, Tossani E. Innovative trends in the design of therapeutic trials in psychopharmacology and psychotherapy. Prog Neuropsychopharmacol Biol Psychiatry. 2013 Jan;40:306-11.

21 Borm GF, Donders R. A treatment should be evaluated by small trials. J Clin Epidemiol. 2009;62(8):887-9.

22 Horwitz RI, Singer BH. Why evidence-based medicine failed in patient care and medicinebased evidence will succeed. J Clin Epidemiol. 2017 Apr;84:14-7.

23 Lobitz G, Armstrong K, Concato J, Singer BH, Horwitz RI. The biological and biographical basis of precision medicine. Psychother Psychosom. 2019;88(6):333-40.

24 Fava GA, Rafanelli C. Iatrogenic factors in psychopathology. Psychother Psychosom. 2019;88(3):129-40.

25 Medication Overload: America's Other Drug Problem. Brookline, MA, Lown Institute, April 2019 